\title{
Filosofía de la ambigüedad o el ambiguo lugar de las mujeres*
}

\author{
María Luisa Femenías**
}

\section{Resumen}

El feminismo de Beauvoir se inscribe en la Filosofía Existencialista, y dos de sus ensayos, a diferencia de la producción de Sartre, están dedicados por entero a cuestiones éticas. En este artículo analizo brevemente esos dos ensayos: Pyrrhus et Cinéas, escrito en 1944, y Pour une morale de l'ambigüité de 1947, redactado dos años antes de la publicación de El segundo sexo, donde desarrolla métodos, y problemáticas propias. Además rastreo sus primeros ensayos en búsqueda de sus conceptos fundamentales, en especial aquellos en los que difiere de la interpretación sartreana —como «libertad», «situación», «proyecto» o «cuerpo»para mostrar que no fue su mera seguidora, sino que se instaló como una auténtica filósofa del siglo XX. También recupero brevemente la influencia de Merleau Ponty, apoyándome en un texto literario - Una muerte muy dulce- y en otro ensayo, menos conocido, que Beauvoir dedicó al Marqués de Sade - ¿Hay que quemar a Sade?-. Beauvoir refuta su moral libertina $e$ individualista, subrayando que no estamos solos en el mundo y que, en tanto cada hombre es plenamente real, todo crimen ultraja realmente. Así, desde una toma de posición propia de la denominada "filosofía de la ambigüedad", Beauvoir pone de manifiesto que es precisamente en la dimensión moral donde la existencia humana se asume como verdaderamente humana. Por eso, uno de los objetivos de este artículo es llamar la atención sobre su originalidad y compromiso ético.

Palabras clave: Moral, Ambigüedad, Humanidad, Proyecto, Libertad, Situación.

* Recibido el 29 de mayo de 2019, acceptado el 17 septiembre de 2019.

** Profesora consulta de la Universidad Nacional de La Plata, La Plata, Argentina. mlfeme@yahoo.com.ar / http://orcid.org/0000-0003-1144-1197 
Philosophy of Ambiguity, The Ambiguous Place of Women

\begin{abstract}
The feminism of Beauvoir is inscribed in the field of existential philosophy, and unlike Sartre's work, her essays are dedicated completely to ethical issues. In this article I briefly analyze two essays; Pyrrhus et Cinéas, written 1944, and Pour une morale de I'ambigüité, of 1947, published before The Second Sex, at a time she was developing her own methods and problematics. I also trace her first essays in search of her fundamental concepts, in particular those in which she differs from Sartrean interpretation such as "freedom", "situation" "project" and "body" - to show that she was not merely his follower, but established herself as an authentic 20th century philosopher. I also briefly review the influence of Merleau Ponty, supported by the literary text, $-A$ Very Easy Death, and another essay, less known, that Beauvoir dedicated to Marqués de Sade - Must We Burn Sade? Beauvoir refutes his libertine and individualistic morals, emphasizing that we are not alone in the world and that, therefore, given that each man is real, all crimes are real violations. Thus, by taking her own position in the so-called "philosophy of ambiguity", Beauvoir expresses that it is precisely in the moral dimension where human existence becomes truly human. For this reason, one of the objectives of this article is to call attention to her originality and ethical commitment.
\end{abstract}

Keywords: Moral, Ambiguity, Humanity, Project, Freedom, Situation. 
El feminismo de Beauvoir se inscribe dentro de los parámetros comprensivos de la Filosofía Existencialista, denominación que debemos a Gabriel Marcel (Beauvoir, 1960). Se desarrolló en Francia a partir de finales de la década de los treinta y hasta después del Mayo Francés, manifestándose como un movimiento amplio que superó los límites de una mera corriente filosófica (2008). Como se sabe, fueron sus miembros más conocidos Jean Paul Sartre, Maurice Merleau-Ponty, Albert Camus y Simone de Beauvoir, pero también Karl Jaspers, Gabriel Marcel, entre otros. A simple vista, esto implica una pluralidad de posiciones, una fuerte interdependencia respecto de algunos supuestos teórico-filosóficos básicos compartidos y no pocas disidencias. En la línea atea, por ejemplo, se han subrayado las divergencias entre Sartre y Merleau-Ponty, pasando casi desapercibidos hasta tiempos muy recientes los disensos teóricos entre Jean Paul Sartre y la propia Simone de Beauvoir, habitualmente considerada una mera acólita suya, tal como lo hace Judith Butler (1998) aún en la década de los ochenta del pasado siglo. Ante los ojos de la crítica filosófica y del público en general, Beauvoir, compañera sentimental de Sartre, era la mera seguidora fiel de las enseñanzas de su compañero-maestro y supuestamente una sombra de su filosofía. Los/as lectores de la época no supieron reconocer la originalidad de su obra, que desbordó la dependencia y la subsidiariedad de sus colegas varones.

Iris M. Young fue quizá una de las primeras que intentó explicar una teoría estructural de la dominación patriarcal esbozada por Kate Millet y Sulamith Firestone-, advirtiendo con agudeza que más allá del sistema de ideas, símbolos, modos de concienciación y variables singulares de mujeres y varones, era necesario indagar y explicar las maneras en que los varones concretos se apropian de los beneficios también concretos que obtienen de las mujeres de su entorno, ya sea de modo real, simbólico o supra estructural (Young, 1983). La relación entre varones y mujeres letrados, poetas o plásticos no era una excepción. El análisis de Young puso de manifiesto la densidad 
del problema y mostró cómo, independientemente de rasgos individuales de carácter psicológico, las diferencias jerárquicas entre varones y mujeres se mantienen en el tiempo, sostenidas por una suerte de ideología metafísica, que acumula siglos de anisomorfismo valorativo a la hora de examinar los lugares que, entendidos como naturales, varones y mujeres ocupan en la sociedad.

Pasaron por lo menos dos décadas hasta que la figura de Simone de Beauvoir comenzó a agigantarse. Cuando su filosofía empezó a investigarse por su propio peso, pudieron verse los singulares aportes de su pensamiento y la influencia conceptual recíproca que circuló entre Sartre y ella. Como lo ha puesto de manifiesto la exégesis iniciada en ocasión del cincuentenario de la publicación de El segundo sexo (1949), cada día se hizo más evidente que no fue meramente la "musa inspiradora" de Sartre, sino que, además del vínculo afectivo y personal que los unió toda la vida, entablaron un debate filosófico, cuya influencia recíproca, plena de coincidencias y de disensos, todavía está por valorarse en toda su dimensión. Como lo ha señalado Magda Guadalupe dos Santos, retomando a Michèle Le Doeuff, el carácter especulativo del pensamiento de Beauvoir fue capaz de proponer nuevas formas discursivas. Esto la instala como una verdadera filósofa, sustentadora de valores y problemáticas propias, que marcaron la segunda mitad del siglo XX bajo la figura de "filosofía de la ambigüedad" (Guadalupe dos Santos, 2009).

Como no podemos revisar todas y cada una de las claves que aporta Beauvoir, en las páginas que siguen analizamos brevemente dos ensayos: Pyrrhus et Cinéas, escrito en 1944 (Beauvoir, 1965), y Pour une morale de l'ambigüité de 1947, redactado dos años antes de la publicación de El segundo sexo (Beauvoir, 2010). ${ }^{1}$

\footnotetext{
1 Publicado como Para una moral de la ambigüedad (1956). Para más información sobre las traducciones al castellano de la obra de Beauvoir, cf. Cagnolati, B.; Forte Mármol, A.; Gentile, A. M. y Vieguer, F. (2010); Cagnolati, B., Femenías, M. L. y Vukovic, J. (2019).
} 
Ambos responden a lo que su autora denominó su "período moral" (période morale) que se inicia en 1939, casi al comienzo de la Segunda Guerra Mundial, y culmina a finales de la década de los 40. En ese período, ante la conmoción del nazismo, su interés se centra en la ética, preocupándose por dos problemas fundamentales, según declara en sus memorias (Beauvoir, 1960). ${ }^{2}$ Por un lado, los fines de la existencia humana y, por otro, las relaciones con los otros (o relaciones intersubjetivas), sobre ambas cuestiones se inscribe la historia del ser humano. Beauvoir quiere mostrar que la libertad (liberté) es el único fin capaz de justificar las acciones de los hombres y el fundamento de todo valor particular de la existencia humana. ${ }^{3}$ Dado que los seres humanos estamos vinculados los unos a los otros de modo fundamental $e$ interdependiente, todo proyecto es ante todo un "proyecto con los otros". Es decir, como destino nos rige la dependencia y la responsabilidad moral mutuas en aras de la libertad de todos los hombres (Beauvoir, 1960).

¿Para qué la acción?

En ¿Para qué la acción? Beauvoir apela a un supuesto diálogo entre Pirro y Cineas - dos personajes de Vidas Paralelas de Plutarco- para proponer una lectura existencialista sobre los fines de la vida. El primero es un conquistador ambicioso y el segundo, cauto y reflexivo, constantemente se pregunta: ¿Y después qué? ¿Para qué? ¿Por qué no descansar entonces, inmediatamente? ¿Para qué comenzar si hay que detenerse? (1965:9). Con este relato, que sigue claramente la línea ensayística de los moralistas franceses (Femenías, 2010), Beauvoir, en un pasaje en el que examina la filosofía de Hegel, lo critica por no

\footnotetext{
2 Beauvoir relata en estas memorias cómo forjó ambas obras; tema en el cual no entraremos. Cf. Abellón (2017).

3 Llamamos la atención sobre el concepto de "hombre" tanto en Beauvoir como los demás existencialistas, ajeno a las interpretaciones postmodernas y postfundacionalistas. Contra la lectura de Butler en "Sexo y género en El segundo sexo de S. de Beauvoir" (1998). Cf. también, Fraisse (2008).
} 
reconocer su fracaso existencial con su fuga hacia la unidad sintética del Espíritu Absoluto. No es la primera vez en que Beauvoir rechaza el punto de partida de lo Absoluto en Hegel a favor del Existencialismo, que a su juicio representa "el paradigma filosófico-existencial del esfuerzo por avoir à être, gracias a cuyo fracaso se encuentra la auténtica afirmación de la existencia humana". En consecuencia, Beauvoir reemplaza la idea de "Totalidad espiritual", con la que Hegel encubre la ambigüedad y el fracaso existenciales, por "la existencia misma" (Abellón, 2017:76), un punto arquimídeo que, en un sentido materialista, implica partir del aquí y el ahora de la existencia. En sus memorias leemos:

Este diálogo de Pirro y Cineas [¿Para qué la acción?] me recuerda al que se desarrolló desde mí misma para mí misma y que anoté en mi cuaderno íntimo el día que cumplí veinte años; en ambos casos una voz preguntaba: “¿Para qué?" En 1927, había denunciado la vanidad de las ocupaciones terrenales en nombre de lo absoluto y de la eternidad; en 1943, invocaba la historia universal contra la finitud de los proyectos singulares: siempre invitaba a la indiferencia y a la abstención. Hoy [1960] como ayer la respuesta es la misma: yo oponía la razón inerte, la nada, el todo, a la ineluctable evidencia de una afirmación viviente (Beauvoir, 1960:456-457).

Beauvoir pone profundamente en cuestión las acciones de los hombres; cada nueva acción nos arroja a una tarea nueva, y otra, y otra, sin descanso. Todo proyecto humano parece absurdo, inexistente si no se le asignan límites, y esos límites son siempre franqueables. Cabe preguntarse ¿Por qué quedarme aquí? ¿Por qué ir más allá? ¿Por qué razón?” (1965:10). La filosofía no vale sin esfuerzo -sostiene Beauvoir-, el ser humano tiene la posibilidad de superar sus propios límites y en esa superación siembra, lucha, conquista, desea, ama, aunque siempre haya un después (1965:14). Por tanto ¿hasta dónde irá el hombre con sus decisiones, con sus actos? ¿Para qué la acción? ¿No es el 
hombre acaso extranjero en el mundo? (1965:16) El ser humano puede establecer relaciones totalmente exteriores con los objetos (1965:17), pero también puede extender su lugar sobre la tierra, dilatar su ser más allá de los límites de su cuerpo y de su memoria: puede trascender. Los objetos permanecen extraños a cada quién; pero al propio ser no se lo puede reconocer sino ahí donde hay compromiso. Este objeto (o cualquier otro) "me pertenece" externamente, porque lo único que en realidad me pertenece por completo es mi acto, porque es lo que yo soy (1965:18). Por tanto, lo único realmente mío es precisamente "el cumplimiento de mi proyecto". Y ese proyecto, se hace en el mundo en un movimiento hacia el otro: un prójimo (1965:19), una trascendencia. Un objeto se nos escapa; una fotografía coagula el instante (1965:23); pero, porque - citando a Heidegger- "El hombre es un ser de lejanías" (1965:28), sólo proyectando el instante al porvenir, el hombre se hace trascendencia (1965:29). Así, "los únicos lazos seguros entre los hombres son aquellos que ellos mismos han creado trascendiéndose en un mundo común mediante proyectos comunes". Es decir, Beauvoir impugna la existencia a priori de una relación esencial entre un "Yo" y un "Otro" (como en Martin Buber), sobre la cual la conducta deba regularse en abstracto (Beauvoir, 2000). De modo que, contrariamente a lo sugerido por Pirro, el fin del hombre no es el descanso, donde sólo caeríamos en el aburrimiento de la vida, sino que ese "volverse hacia los hombres" implica "encontrar en la propia humanidad ese fin absoluto que, en primer término, el hombre había buscado en el cielo (1965:47). Como para todos los existencialistas, la propuesta de Beauvoir es que el hombre es proyecto, y que en su responsabilidad ante el proyecto reside su libertad. Lo que somos, lo somos sobre la base de una situación de hecho que hacemos nuestra y transformamos sin cesar por una especie de escape que, a diferencia de Sartre, nunca es una libertad absoluta, incondicionada o metafísica, sino fáctica.

El proyecto es exactamente lo que quien lo hace decide que sea y tiene un sentido que no puede definirse desde afuera: "Cada hombre decide el lugar que ocupa en el mundo; pero es necesario 
que ocupe uno, jamás puede retirarse" (1965:34). Porque hombre no se es sino eligiéndose mediante actos, y quien se rehúsa a elegir, se aniquila; rehusar la acción es aproximarse a la cosa. En un texto posterior, Beauvoir sostiene incluso que "El rico que acepta pasivamente sus privilegios no existe más que en el modo de ser de una cosa" (Beauvoir, 2000:89). Esa es la paradoja de la condición humana: todo fin puede ser superado y, no obstante, el proyecto define al fin como tal. En otras palabras, para superar un fin es necesario, en primer término, haberlo proyectado como algo que no va a ser superado; pero luego hay que superarlo. Paradojalmente, el hombre no tiene otro modo de existir: "Un hombre no encuentra su lugar en la tierra sino transformándose para los otros hombres en un objeto dado; y todo lo dado está destinado a ser trascendido" (1965:51). Incluso "Si pongo un hijo en el mundo, él será tal vez mañana un malhechor, un tirano; [pero] él es quién decidirá y cada uno de los hijos de esos hijos decidirá por sî" (1965:54). Así pues, como yo, el otro, a solas consigo mismo, experimenta un vacío en su corazón, "un hueco siempre futuro" (1965:56) y aun siendo alguien distinto de mí, "creo en su ser" (Beauvoir, 2000:95). ${ }^{4}$ Yo que no soy nada, creo en su ser y en que él es también otra cosa que un objeto: la infinitud de su existencia puede extender sin cesar el horizonte hacia el cual se arroja.

Ahora bien, no hay en Beauvoir un optimismo hegeliano ni en la superación de la síntesis, ni el hombre en el cumplimiento del propio proyecto se recuperará en el devenir universal (1965). ¿Y después? Y después se verá (1965:63). Férrea existencialista, Beauvoir argumenta nuevamente a favor de la libertad del

${ }^{4}$ Como Sartre, apela a un argumento por analogía, garantía débil de que el otro individuo siente, sufre, etc., como yo. Beauvoir, sin embargo, se apoya en este tipo de argumentos para objetar el solipsismo hedonista de Sade, quien sostiene: "para mí no hay verdad más que la envuelta en mi experiencia, y la íntima presencia del otro, escapa radicalmente a ella, pues no me concierne y no puede dictarme ningún deber" y "No hay ninguna comparación posible entre lo que sienten los demás y lo que nosotros mismos sentimos" (Beauvoir, 2000:95). Que en el mundo hay otros "yo" es un factum que no puede negarse. 
hombre; un hombre que no puede jamás abdicar de su libertad porque cuando pretende renunciar a ella no hace sino enmascararla, y la enmascara libremente para huir de la responsabilidad individual (como contra cara de la libertad). Obedecer, a dios, a un amo, al tirano, al padre, a la naturaleza o a quién fuere, es sólo "elegir obedecer" respondiendo a un llamado que emana de la propia voluntad. Porque "el hombre no es sino eligiéndose y si se rehúsa a elegir, se aniquila" porque "el hombre no tiene otro modo de existir" que en tanto libertad (1965:63) y en tanto libertad debe hacerse cargo de ella.

El Otro está radicalmente separado; es pura interioridad que me es escamoteada. No obstante, sabemos que no estamos solos en el mundo (1965) y que cada uno de nuestros actos crea una situación nueva a la que todos debemos responder, comunicándonos los unos con los otros, porque los otros sólo existen para mí cuando entran en relación conmigo. Uno frente a otro/a, esa es la situación. En suma, suspendida en un vacío, la humanidad sólo es libre para la acción trascendiendo toda trascendencia (1965).

La humanidad como fin de la existencia

Enmarcando al hombre en la fugacidad del acontecimiento, Sartre sostiene que "se define por su proyecto" (Sartre, 1963). Este ser material supera perpetuamente su condición por su acción y por su gesto. Sin embargo, no debe confundirse "voluntad" con "proyecto". Mientras que la "voluntad" es una entidad abstracta, el "proyecto" es una praxis en "perpetua producción de sí mismo por el trabajo"; no es ni una necesidad ni una pasión, tampoco una voluntad, sino que

(...) nuestras necesidades, nuestras pasiones y nuestros pensamientos participan de esa estructura: siempre están fuera de ellos mismos hacia... Esto es lo que llamamos existencia, no entendiendo por ello una sustancia estable que descansa en sí misma, sino un perpetuo desequilibrio, un arrancamiento de sí de todo el cuerpo. (...) un impulso 
(...) que se proyecta a través de un campo de posibilidades, algunas de las cuales realizamos, excluyendo otras; también lo llamamos elección o libertad (1963:119, subrayado en el original)

El ser humano, tanto para sí mismo como para los demás, es un ser significante y nunca se "puede comprender el menor de sus gestos sin superar el puro presente y explicarlo con el porvenir." Por eso, el sentido de la comprensión es simultáneamente progresivo (hacia el mundo objetivo) y regresivo (elevándome a la condición original) (v.I:121). ${ }^{5}$ Ahora bien, estamos en un mundo con otros y nuestra comprensión de esos otros nunca es contemplativa, por el contrario, implica convivencia, relaciones concretas y humanas, praxis y hechos colectivos. ¿Qué puede haber de más exacto y riguroso que estudiar al hombre, reconocerlo en sus propiedades humanas, inspeccionando el campo social de relaciones, de estructuras, de empresas humanas con otros hombres reales, las acciones, y las instituciones que tienen lugar según esta relación? (subrayado en el original, v. I:123). Si el método a emplear debe ser dar cuenta de la "razón dialéctica", se la debe aprehender allí donde se "deje ver", apartándose de los dogmatismos (v. I:166).

Leídas detenidamente las palabras de Sartre tienen un fuerte eco beauvoiriano, al menos tal como las había presentado años antes en ¿Para qué la acción? Beauvoir propone que fijemos primero la mirada en cada uno de nosotros para analizarnos, definirnos, conocernos y asumir nuestra propia libertad comprometida con el mundo; una libertad que se hace con conductas y acciones que responden a preguntas en primera persona como: ¿Qué hacer? ¿Qué creer? (1956:47). También en Para una moral de la ambigüedad emprende Beauvoir el estudio de la libertad de los individuos y cómo entenderla, siempre subrayando la importancia de la responsabilidad individual.

5 Beauvoir propone el método progresivo-regresivo en El segundo sexo, que Sartre reinterpreta. Cf. López-Pardina (1998); Casale (2010); Femenías (2008). 
Nuevamente, años más tarde retomando una sentencia de Sade - "En una sociedad criminal, es necesario ser criminal"Beauvoir niega validez a la afirmación del pensador libertino y, partiendo de sus propias palabras, en nombre del individuo, elabora una firme crítica: No estamos solos en el mundo y "pues[to que] el individuo es completamente real, el crimen lo ultraja realmente" (Beauvoir, 2000:95). No hay, pues, descargos a la libertad/responsabilidad de elegir: toda "obediencia" no es más que una fuga de la libertad de "elegir obedecer" y hay que hacerse cargo de ello. No obstante, sobre todo en El segundo sexo, Beauvoir indaga los matices que marcan cada elección-situación. Porque toda acción está doblemente limitada por la "situación" y por el modo en que se la "lee". Es ahí donde yace la ambigüedad.

¿Moral de la ambigüedad? ¿Cuerpos en la ambigüedad?

Este subtítulo invita a considerar dos cuestiones: por un lado "la ambigüedad"; y, por otro, la relación entre los cuerpos y la moral. ¿Qué es la ambigüedad? ¿ ¿Una expresión, un hecho, una palabra? En sus novelas, Beauvoir da buena cuenta de la ambigüedad de las situaciones, de las palabras y de los comportamientos de personas y de personajes. Sartre también. ¿Adjetivos, sustantivos, acciones ambiguas? ¿Morales ambiguas? ¿Cómo entenderlos? ¿Cómo despejar equívocos? ¿Cómo precisar sentidos? ¿Cómo establecer la ambigüedad de los cuerpos y de la moral?

Beauvoir considera el "develamiento del ser" como una dimensión del ser humano que convierte el vano deseo de ser (la "pasión inútil" como la había denominado Sartre), en una asunción de la existencia. Según relata Teresa López Pardina, en febrero de 1945, Beauvoir le comentó a Misrahi, discípulo de Sartre, que se podía fundar una moral si se convertía el vano

6 Su raíz etimológica proviene del latín ambiguus, que significa "aquello que no tienen un sentido o un significado único y que por tanto puede interpretarse de diferentes maneras, que pueden generar confusión o indeterminación" Coramidas (1998). 
deseo de ser en una asunción de la existencia. Misrahi la animó a hacerlo, y así se gestó el ensayo Para una moral de la ambigüedad (López-Pardina, 2013).

Más próxima a Merleau-Ponty que a Sartre, Beauvoir apela a la noción de ambigüedad remitiendo a la situación del hombreen-el-mundo. En el sentido heideggeriano de ser-en-el-mundo, Merleau Ponty reconoció que el hombre era un être-au-monde, aunque se opuso al intelectualismo racionalista sin renunciar a una filosofía del sujeto de raigambre husserliana (González, 2011). Eso lo llevó a atribuir a la noción de cogito cartesiano una ambigüedad que se corresponde con una doble y simultánea consideración. Por un lado, pertenecer al mundo y, por otro, distinguirse de él (Femenías, 2010). ${ }^{7}$ Es cierto que tenemos conciencia de nuestro cuerpo en el mundo (Álvarez-González, 2011), como en el Sartre del cogito prerreflexivo, y que mi cuerpo es el centro del mundo, alrededor del que todo objeto gira, porque, en cierto sentido, "mi cuerpo es el quicio del mundo". La paradoja aparece porque Merleau-Ponty adopta una posición anti-idealista y, al mismo tiempo, mantiene su punto de vista fenomenológico.

Sin embargo, contrariamente a Descartes, "el yo que piensa y que quiere" no es para Merleau-Ponty distinto del propio cuerpo. Por eso, ni él ni Beauvoir pueden considerar al cuerpo como un objeto más en el mundo: mi cuerpo es el medio de mi comunicación con todos los objetos del mundo; es el horizonte de mi experiencia. Debemos a Merleau-Ponty la conciencia de nuestros cuerpos, no como objetos, sino como experiencia preobjetiva del cuerpo (Álvarez-González, 2011). Es decir, que la conciencia-que-tengo-del-cuerpo equivale al cuerpo-que-se-haceconsciente de un modo prerreflexivo. Si el cuerpo es la cosa del "yo pienso" en Descartes, para Merleau-Ponty como para

\footnotetext{
7 Una distinción afín elaboró Heidegger con el concepto de "diferencia". Sintéticamente, adoptó un principio de "identidad" (Identitat) de tipo metafísico, garantía de la mismidad, vinculado a la "diferencia" como Unterscheid y como Differenz. Distingue así entre pluralidad óntica (diferencia entre un ente y otro) y diferencia ontológica (cada ente respecto del Ser). Cf. Heidegger (1990); Femenías (2010).
} 
Beauvoir, "Yo soy mi cuerpo". Y, como subraya Beauvoir, "mi cuerpo" es un cuerpo sexuado, con marcas diferenciales (Beauvoir, 1954:20). En un sentido, "mi cuerpo" es aquello que precede mi distinción entre sujeto y objeto y un sistema sinérgico cuyas funciones se recogen y se vinculan en el movimiento general del être-au-monde como figura estable de la existencia. ${ }^{8}$

De modo que la conciencia es, más bien, "un tejido de intencionalidades". El sujeto que piensa es el mismo que el que siente y que el que experimenta (o vivencia) el mundo a través de su cuerpo. La vida de la conciencia es una totalidad que proyecta intencionalmente la situación en la que nos hallamos alrededor de nosotros como un "acto intencional." Es decir, se vive la unidad del sujeto y la unidad intersensorial de la cosa; no se los piensa. Por eso, por un lado, mi cuerpo-yo determina la textura de los objetos y les da sentido; pero, por otro, permanece como una alteridad efectiva. Sin embargo, lo dado ni es la cosa ni es la idea sino la experiencia de la cosa, cuya percepción es antes que nada una vivencia que no rompe mi vivencia primordial de que hay un mundo anterior a toda mi experiencia concreta. "Así, pues, yo soy mi cuerpo, al menos en la medida en que tengo uno, y, recíprocamente, mi cuerpo es como un sujeto natural, como un esbozo provisional de mi ser total" (Beauvoir, 1954; López Pardina, 2009:102; Merleau-Ponty, 1985:165)

En Para una moral de la ambigüedad, Beauvoir plantea una serie de aporías vinculadas al cuerpo, al yo, y a la situación, que retoma en todas sus obras subsiguientes. Sobre todo en El segundo sexo, pero también, como muchos críticos lo han advertido, en su obra literaria, Beauvoir ilustra algunas de las nociones que elabora teóricamente. Eso sucede con la mala fe (en el caso de las mujeres que son víctimas-cómplices del sometimiento), la de opresión inflingida (cuando ese sometimiento no es consentido, pero sí padecido) y especialmente la libertad, la situación y la ambigüedad. En su obra literaria y en sus textos

${ }^{8}$ La distinción castellana entre "ser" y "estar" dificulta la traducción y el sentido de la afirmación. 
ensayísticos, esos conceptos aparecen entramados formando un sistema que da coherencia a su proyecto creador (Ferrero, 2006). ${ }^{9}$

Pongamos por caso Una muerte muy dulce donde Beauvoir narra los últimos días de vida de su madre, víctima de una enfermedad terminal (Beauvoir, 1965). La narración, fiel al método fenomenológico, hace un relato pormenorizado del rol de la maternidad en la sociedad occidental y de su lugar simbólico. Implacable, Beauvoir describe el deterioro físico de su madre, y, al mismo tiempo, indaga las complejas relaciones que mantuvo con ella, con su hermana y con su padre. A su juicio, las diferencias que la separan de su madre y el modo en que ambas construyeron respectivamente su femineidad, ponen en evidencia el progreso de las mujeres: han accedido a una mejor educación, tienen más poder de decisión, exigen derechos desafiando el destino que la sociedad les había prescripto. Ahora, ¿̇son las experiencias de vida las que predisponen a afrontar la experiencia de la muerte? En ese punto, la existencia humana enfrenta sus propias ambigüedades; trágicas ambivalencias que desembocan sine qua non en la muerte como único horizonte universal, aunque -contra Heidegger-el hombre no sea un ser-para-la muerte (Beauvoir, 1965).

Cada individuo singular vive en el contexto de su libertad y se manifiesta en su propio proyecto, construido sobre esa realidad ambigua que se llama existencia, y que no existe sino haciéndosela (1954:73). Las "nuevas mujeres" con las que Beauvoir compara a su madre moribunda han luchado por sus conquistas, alcanzado logros y vivido frustraciones. Pero la situación de las "nuevas mujeres" se apoya en los logros de generaciones que las antecedieron: sus propias "madres" sanguíneas o simbólicas. Esto no quiere decir que Beauvoir misma no hubiera tenido que enfrentar a su familia y a todos los prejuicios de clase y de género de su época. Para ejercer su propia libertad y su propio proyecto debió chocar, aliarse, distanciarse y aceptar los proyectos de/con los otros. La delicadeza metafórica, con que describe la muerte, exhibe un sustrato ético de

9 Tomamos la noción de "proyecto creador" de Pierre Bourdieu (1967). 
configuraciones de existir histórico, de situaciones que quedaron plasmadas en su literatura. Como figura de la ambigüedad, la muerte personifica la alteridad absoluta de la existencia (Guadalupe dos Santos, 2009). Y, en la ambivalencia pendular de existencia y muerte se desenvuelve una moral ambigua hecha de encuentros y desencuentros.

Existir tiene sus incongruencias. La existencia no es clara, no es lineal, no es siquiera coherente: por eso, con Merleau-Ponty, para Beauvoir un cuerpo es sobre todo un "cuerpo vivido" y el sexo, "un sexo vivido". Un extraño juego de inclusiones y exclusiones hace que los seres humanos experimentemos esa "trágica ambigüedad" de la vida. No se puede negar la vida; no se puede suprimir la ambigüedad. La ambigüedad es propia de la condición humana en tanto se define en relación con lo Otro, la categoría más antigua que se conozca (Beauvoir, 1954). "Yo soy parte de este mundo, no un mero espectador". Y esta inherencia explica mi finitud, pero también mi apertura. Mi situación -en tanto yo soy cuerpo- es lo que me limita, pero también lo que me comunica con todas las cosas. Mi cuerpo es la cosa para la que hay cosas; la cosa y el mundo me son dados con mi cuerpo en una conexión activa (Álvarez González, 2011).

En suma, para Beauvoir, como para Merleau-Ponty, el cuerpo determina nuestra situación y constituye la estructura de la existencia, a la cual pertenece también el poder de trascender. La existencia es, por tanto, un movimiento permanente en el que cada quien asume una situación de hecho y le concede un sentido cuya trascendencia trasciende. De modo que todas las funciones humanas, en tanto existenciales, son al mismo tiempo biológicas y espirituales, incluida la sexualidad, y revisten siempre la ambigüedad que define todo lo humano. El ser humano no es esencia cerrada y acabada como la piedra. Por el contrario, es apertura, inconclusión, actividad, manifestación de la acción que se proyecta al mundo del que forma parte y al que, al mismo tiempo, revierte en situaciones nuevas en las que todos y cada uno estamos inscriptos (Beauvoir, 1965). Por eso, la unidad de la existencia es confusa y esa confusión es ambigüedad en el cuerpo- 
yo que escribe, que está enraizado en la situación y, a la par, en la libertad.

Libertad y situación

La lectura que hace Beauvoir del mundo, tanto en sus ensayos filosóficos como en sus novelas, se liga fuertemente a las condiciones fácticas de la existencia humana. En consecuencia, crea o se apropia de un conjunto de categorías estrechamente vinculadas a la filosofía existencialista - proyecto, destino, situación, libertad, liberación, trascendencia, ambigüedad- que cobran una particular relevancia en sus análisis teóricos. ${ }^{10} \mathrm{Y}$, quizá, porque la moralidad de cada ser humano se mide en términos de su capacidad de acción, el horizonte de la acción moral está dado por su experiencia individual y su posibilidad de universalización, bajo la pregunta ¿̇cuáles son los límites de mis proyectos como ser humano en relación a los otros seres humanos? (Femenías, 2008). De modo que para analizar la "acción" en general y la "acción moral" en particular hay que examinar nuevamente las nociones de "situación" y de "libertad", ambas estrechamente relacionadas.

Ahora, si como sostiene Sartre, los sentidos y los significados "están en el mundo" y son parte del factum de la existencia humana, está en cada uno de nosotros/as apropiárnoslos desde la singular situación que nos constituye (Beauvoir, 2000). ${ }^{11}$ La situación es, pues, el afuera de la libertad y está constituida por el mundo, las cosas y los otros, que pueden ser un obstáculo infranqueable o constituirse en posibilitadores máximos de la libertad de cada quien. Si cada conciencia no es testigo más que a partir de sí, y los valores no pueden invocar ningún derecho natural que imponer al otro, sólo se los puede reivindicar de

\footnotetext{
10 También, Sartre (1978); Merleau-Ponty (2012).

${ }^{11}$ Beauvoir sostiene: "nuestros gustos son motivados no por las cualidades intrínsecas del objeto sino por la relación que éste tiene con el sujeto"; es decir, un objeto carece de cualidades per se, intrínsecas, más allá de la significación que le damos y que lo sobrepasa.
} 
manera singular y viviente en los actos (Beauvoir, 2000): en la acción. La ambigüedad se define en la acción y en la interpretación, aunque nunca por completo, porque la acción no cesa y los significados ni son estáticos ni responden a esencias que los determinen. Como subraya López Pardina, apelando a la terminología beauvoiriana, se trata de una hermenéutica siempre contextualizada por la situación de quien la utiliza: en el caso de Beauvoir, la de una persona privilegiada por sus extraordinarias dotes intelectuales, por la atmósfera cultural familiar y por una sólida formación académica, que su situación de mujer contribuyó a aguzar sin duda alguna sobre la observación de la conducta y la situación de los demás (López Pardina, 2012; Fraisse, 2008).

Es verdad que para Beauvoir (1956) la libertad se encuentra primero, como vimos, en cada individuo, pero no acaba ahí. Si bien "La moral es el triunfo de la libertad sobre la facticidad; el subhombre sólo realiza la facticidad de su existencia; [porque] en lugar de engrandecer el reino humano, opone a los proyectos de los otros hombres su resistencia inerte" (Beauvoir, 1956:45). En principio porque debe comprender que cada hombre depende de los otros y lo que a cada quien le llega de los otros depende de cada uno en cuanto sentido; es decir, interpretación. Esa libertad, entonces, se encuentra en el individuo que la ejerce, pero ni es "exclusiva" o "excluyente" de los otros, ni es un modo de "egocentrismo". Por el contrario, es una libertad personal como derecho universal; es de "mi vida" tanto como de "mi vida con los otros". Por eso, habiendo comprometido toda la vida en la libertad, trágica y paradójicamente "mi libertad depende de los otros" (Beauvoir, 1956:63).

En ¿Para qué la acción? Beauvoir dedica un capítulo completo a la noción de "situación", con la que termina la parte I del libro. Mientras que para Sartre el concepto de situación apunta a la afirmación de la libertad absoluta del sujeto, concibiendo la situación como un "producto" de la interpretación que la libertad del sujeto hace del en-sí contingente (Sartre, 1971), para Beauvoir, en cambio, en la situación no siempre existen las mismas posibilidades de interpretación y de realización de la libertad. 
Como sostiene Celia Amorós, retomando palabras del propio Sartre, estamos "condenados a ser libres". En Cahiers pour une morale Sartre mismo se lamenta -continúa Amorósreconociendo (Sartre, 1983) ${ }^{12}$ :

Nunca he comprendido bien lo que [eso] significa (...) Sin embargo, es la base de mi moral. Partamos del hecho de que el hombre es en-el-mundo, es decir, al mismo tiempo una facticidad investida y un proyecto-superación. En tanto que proyecto asume, para superarla, su situación (...) Toda superación que no se conserva es una huida a la abstracción. Solamente puedo desembarazarme de mi situación de burgués, de judío, etc. si la asumo para cambiarla (Amorós, 2008:58).

Para Sartre el proyecto se asume para superar la situación. La libertad tiene, pues, como las monedas, un reverso que es la facticidad. Si para Sartre la situación no es el límite de la libertad, para Beauvoir, en cambio, la situación siempre delimita el alcance de la libertad. Por eso, tanto en ¿Para qué la acción? como en Para una moral de la ambigüedad, el peso de lo exterior contingente es mucho mayor que en Sartre.

En Para una moral de la ambigüedad, se distancia fuertemente del planteo metafísico de Sartre, e introduce la novedosa concepción de que las situaciones se jerarquizan de modo tal que abren o cierran espacios de libertad. Hay situaciones privilegiadas en las que la libertad se cumple en grado máximo y otras en las que las posibilidades de su realización son mínimas. Situaciones como la de las mujeres del harén, los esclavos negros o los parias de la India, son ejemplos patentes de grados mínimos de libertad (Beauvoir, 1956; 1954); la situación la limita en mayor o en menor medida, además de ser su condición fáctica de posibilidad. La facticidad (lo dado) para perpetuarse debe

\footnotetext{
12 Sartre la anuncia al concluir El ser y la nada, pero no la escribe nunca. Solo quedan notas tomadas entre los años 1947 y 1948, publicadas en Gallimard por Arlette Elkaïm-Sartre en 1983.
} 
sobrepasarse (Beauvoir,1956) y, en todos los casos, "lo dado está presente en su sobrepasamiento" (Beauvoir, 1956:81).

Diferenciándose entonces de la moral y de la libertad sartreanas, Beauvoir subraya los condicionamientos sociales de la acción moral. Tanto es así que incluso algunos especialistas concluyen que esta perspectiva habría influido fuertemente en el Sartre posterior, el de la Crítica de la razón dialéctica (LópezPardina, 1998), donde no sólo reconoce la fuerza de los condicionamientos sociales sobre la libertad individual, sino que trata de explicar el funcionamiento de los diversos modos de presión/opresión social. Volviendo a Beauvoir, si el ser humano (varón o mujer) se constituye en sus proyectos y si éstos no se realizan al margen de la libertad en situación, entonces, un margen demasiado estrecho de libertad incide constitutivamente en ese humano. Beauvoir estudia las figuras de la subordinación, las de la fuga, las del sometimiento para mostrar cómo la mengua de la libertad incide no sólo en el cumplimiento de un proyecto sino en quién es y cómo es ese individuo. El segundo sexo da buena cuenta de ello. En otro registro, el famoso prólogo de Sartre a Los condenados de la tierra de Fanon, también (Fanon, 1963).

Ahora bien, cada proyecto concluido es simplemente el punto de partida de otro, enmarcado siempre en el horizonte de la finitud humana. En cada proyecto se entreteje la situación y la libertad de cada quien con el deseo (imposible de satisfacer) de encontrar un fin absoluto en cuyo cumplimiento pretendemos constituirnos como seres plenos. Tarea imposible, sin duda, que lo finito alcance lo absoluto, aunque resuelve la existencia en una búsqueda constante de su contenido. De clara herencia kierkegaardiana, en este campo pendular y ambiguo, la moral beauvoiriana de la responsabilidad individual no admite la aceptación de un hacer que nos propongan otros para constituir nuestras propias vidas bajo el ilusorio descargo de la obediencia. Ilusorio, por cierto, en tanto siempre elegimos, incluso cuando elegimos no elegir. Situación y libertad son pues inseparables y la libertad de los unos se metamorfosea en la situación que será destino de los otros (Beauvoir, 2000). Para Beauvoir, entonces, la 
situación es límite de la libertad (no su contra cara), y cada quién se compromete, de hecho, en nombre de su propia existencia con los otros: Si yo soy libre, tú serás libre pues solo la libertad del otro es capaz de necesitar de la mía (Beauvoir, 2000; 1965).

"¿Cómo conciliar - se pregunta Beauvoir - la presencia de estos límites con la idea de libertad, confirmándose como unidad y movimiento indefinidos?" (1965:29). Para responder distingue entre puissance, como potencia que no tiene límites, y liberté, como libertad fáctica, constitutiva de la realidad humana. .En el primer caso, la puissance implica una suerte de "desde dentro" una potencia infinita; metafísica, casi de estilo sartreano. En el segundo caso, las posibilidades que se le ofrecen al individuo humano concreto implican, como en Merleau-Ponty, que siempre son finitas y que pueden aumentar o disminuir "desde fuera", desde la situación. Son las condiciones (circunstancias) de ese "desde fuera" que inciden y jerarquizan la situación, imprimiendo muy posiblemente alguna cuota de violencia. Incluso "desde fuera" proviene nuestro propio nacimiento, "producto" del proyecto de la libertad de otros, de la cual no fuimos partícipes.

Los límites de la libertad (liberté) tienen además una cara negativa: la opresión que algunos hombres realizan, ejercen y justifican sobre otros. Su origen no está en el "mal" entendido como una entidad metafísica, sino por el contrario, en el ejercicio mismo de la libertad ajena:

Porque hay hombres que no pueden justificar su vida más que por medio de una acción negativa. Ya lo hemos visto, todo hombre se trasciende. Más sucede que la trascendencia está condenada a rodar inútilmente sobre sí misma porque se la separa de sus objetivos. Esto es lo que define una situación de opresión (Beauvoir, 1965:79).

Por tanto, para Beauvoir, la situación en la que se inscribe mi libertad y la de los otros implica mi responsabilidad ante ellos y ante mí mismo/a, y viceversa. Queremos la libertad por la libertad y a través de cada circunstancia particular. Pero, cuando queremos la libertad descubrimos que ella depende enteramente 
de la libertad de los otros, y que la libertad de los otros depende de la nuestra.

Beauvoir ve con claridad que, sin duda, la libertad como definición, como categoría metafísica no depende de otros; pero la libertad fáctica sí; esa es la que a ella le interesa. Por eso se pregunta: ¿Cuál es mi situación ante los otros? ¿Desde dónde efectúo el deseo de asumirme como existente? ¿Cómo evalúo la situación para superarla y trascenderla? Si el respeto por la libertad de otro no es una regla abstracta, sino la primera condición del éxito de mi esfuerzo, entonces sólo puedo dirigirme a la libertad de otro, sin violentarla." En otras palabras, sólo si el otro es libre y yo respeto su libertad, tengo garantizada la mía (Beauvoir, 1965). De la no reciprocidad en el cumplimiento de ese dictum, nace la falta moral, la acción de opresión, la negación del otro como persona. Como yo soy mi "cuerpo vivido", toda la libertad se inscribe en la ambigüedad irreductible de la realidad humana; de un cuerpo "encarnado" que es un cuerpo en situación, desde donde esa libertad se limita y se ejerce a la vez (Amorós, 1999:113).

En ese contexto, Beauvoir apela a la noción avoir à être, de difícil traducción. Su posicionamiento es existencial y difiere del de Heidegger. Si para el filósofo alemán los atributos del ser-ahí son "modos de ser posibles para él" y el Dasein se afirma cuando "se determina como ente, en cada caso, partiendo de una posibilidad que él es y que en su ser se comprende de alguna manera" (Abellón, 2017:77; mi subrayado), Beauvoir en cambio adopta la concepción existencial desde una lectura antropológica de Ser y Tiempo, como la que había introducido Alexander Kojève. En algunas investigaciones, avoir à être se traduce como "tener que ser", basándose en la idea heideggeriana de Zu-sein (Abellón, 2017:77). Sin embargo, la idea de conatus, tal como la entiende Celia Amorós (1997; 2000), nos parece más próxima al pensamiento beauvoiriano.

Conatus es algo más que un participio latino. En textos antiguos es difícil distinguir su uso técnico del vulgar, y también es difícil distinguirlos en las traducciones. Hoy en día, se usa poco en el sentido técnico ya que tanto la física como la biología modernas 
lo han reemplazado por otros conceptos. Sin embargo, fue muy influyente en pensadores del siglo XIX como Nietzsche $y$ Schopenhauer. Amorós lo toma libremente en su versión espinoziana, en el sentido de esfuerzo por "perseverar en el ser". Esto es, deseo de permanecer en orden del ser o de la naturaleza. Ahora bien, el conatus, así entendido, no es algo peculiar del ser humano, ni siquiera de los seres animados; tampoco es instinto o movimiento voluntario. No es el modo en que todo "individuo de naturaleza animada" actúa en aras de su propia conservación y la de su especie. Más bien, es una suerte de tendencia de cualquier cosa singular, animada o no, una piedra o un ser humano, de persistir como es. Si para Spinoza esa era la esencia, tal y como Amorós lo entiende y lo aplica a Beauvoir, es un término que excluye cualquier finalidad inmanente o trascendente; cualquier esencia o determinación consciente y sólo apunta a la permanencia en el ser.

Ahora bien, para Beauvoir, como para Sartre, el hombre no es (n'est pas) porque, no tiene una esencia predada, sino que tiene que hacerse (a à être son être), y su existencia consiste precisamente en la acción (Beauvoir, 1965). Quizás la vida no sea sino un azar cósmico y el homo sapiens solo una excrecencia azarosa de esa vida. Pero, como sostenía Mallarmé, que el hombre sea solo "un ser de azar que niega el azar" (Beauvoir, 1965:31) no hace sino conminarlo a la acción, a un hacerse, que sólo concluirá con su muerte: ahí en el cierre definitivo de la apertura, de la indeterminación, de la elección constante, alcanzará su esencia. El conatus es pues un intento por negar el azar, que se resuelve en la voluntad de legitimar la vida mediante opciones racionales y libres. Si la razón va más allá de sí misma en su propia autocrítica, en la conciencia de sus límites y de su propia posición de razón práctica, el conatus es autonomía y voluntad de auto regulación y entonces es libertad. Es libertad limitada por la situación, que se abre en la incompletitud y en la indeterminación del hombre. Esa incompletitud, esa apertura, esa indeterminación que solo se clausura con la muerte. Así, el hombre se mantiene en un vacío, creado por la reflexión pendiendo de la ambigüedad. Pero puesto 
que ese vacío no es sino el reverso de la reflexión, ahí donde se detiene mi reflexión, se detiene mi porvenir; sólo lanzándome al porvenir incierto, fundo con certidumbre mi presente (Beauvoir, 1965).

Mujeres, situación y libertad

Beauvoir entiende "hombre" en el sentido formal ilustrado de "ser humano", independientemente de su sexo y de sus opciones sexuales, del color de su piel y de su clase social. Sin embargo, la universalidad formal ilustrada tiene sus claroscuros. En la introducción de El segundo sexo, Beauvoir llama la atención sobre la falacia nominal que oculta a las mujeres bajo el universal "hombre", y llama a un estado de alerta respecto del uso de los términos generales. Por tanto, si bien afirma que el hombre que no es, sólo al actuar se hace, advierte que esta sentencia se modula de modo diferente cuando este "hombre" es "mujer" (Beauvoir, 1954). Esta convicción lleva a Beauvoir a especificar los modos en que las mujeres históricamente fueron excluidas del reconocimiento de sus derechos qua humanas, a grandes rasgos, objetivo de El segundo sexo. Por esto, Sonia Kruks considera que precisamente las nociones que Beauvoir analiza y desarrolla en los dos ensayos previos -en especial la noción de "situación", que Beauvoir asume firmemente- son fundamentales para los desarrollos posteriores de las teorías y de las prácticas feministas (Kruks, 1992).

Beauvoir examina y desmonta los límites en que la situación pone a los humanos; indaga y revisa las posibilidades que tienen de lanzarse al porvenir incierto para fundar sus certidumbres; escudriña los espacios de reflexión humanos que alejan de la densidad de la inmanencia. Como Sartre, entiende que es imprescindible comprender cómo funcionan las construcciones sociales impuestas por una sociedad clasista, además marcada por la diferencia sexual. Es preciso desmontar sus mecanismos y generar las condiciones de la vida en libertad, a partir del locus que a cada quien le ha tocado. Y todas las marcas son ambiguas; 
no dependen de relaciones a priori o en-sí. Se debe revisar una y otra vez la situación, porque no debe entendérsela como si estuviera petrificada. Por el contrario, las opresiones responden a razones históricas que hay que develar.

Sin embargo, algo extraño sucede a las mujeres supuestamente incluidas en el universal "hombre": carecen de historia, de individualidad, de proyecto, son simplemente "el eterno femenino". La denuncia no era nueva, pero la Primera Guerra había dejado trunco todo debate al respecto. Concluida la Segunda Guerra, mérito de Simone de Beauvoir (aunque no sólo de ella) fue retomar el hilo que se había cortado décadas antes. Mérito exclusivo de Beauvoir fue haber insertado los reclamos de las mujeres en una construcción filosófica y argumentativa que atisbaba en las articulaciones estructurales de esa invisibilidad.

El estilo ensayístico de El segundo sexo vincula a Simone de Beauvoir a los grandes moralistas franceses: Voltaire, Montesquieu, D'Alembert, Diderot, Gouges, entre otros/as; todo/as alejados del estilo tratadístico que desde Descartes en más había inaugurado la filosofía de la Modernidad. Al recuperar el ensayo, Beauvoir recupera también un debate y una problemática que el siglo XIX denominó la "cuestión femenina", y que se enlazaba profundamente con las luchas ilustradas por la igualdad (Femenías, 2010).

López Pardina identifica en El segundo sexo tres razones históricas por las que las mujeres no pudieron reivindicarse como sujetos: a) porque no tenían medios materiales para hacerlo; b) porque sentían un vínculo de dependencia o de necesidad, que las ataba al varón; c) porque muchas veces se complacían en su papel de Otras como víctimas. Si la última razón constituye una "falta moral" en términos beauvoirianos, pues la mujer se veda a sí misma el ejercicio pleno de su libertad, las otras razones le exigían revisar las estructuras históricas y sociales que favorecieron la caída y permanencia de las mujeres en la inmanencia, más próximas a la cosa que al sujeto humano, como muchos años después lo sintetizaría Catherine MacKinnon. 
Ya en Para una moral de la ambigüedad, Beauvoir (1956) sostiene que un acto es tanto más moral cuanto más abre el horizonte de las libertades propias y ajenas. Los actos de "el hombre" (en términos de varón), que cerraron los espacios de libertad de las mujeres, deben asumirse y censurarse como faltas morales porque impidieron por siglos a las mujeres prolongarse a través de la libertad de/con los otros, de sobrepasar la muerte y realizarse como una unidad indefinida. Sólo se les permitió trascender en la materialidad de la carne con la maternidad. Y, si una acción es inmoral cuando suprime o reprime las libertades de los otro/as, es decir, cuando una libertad no se abre a otras libertades, sino que simplemente las coarta, es opresión y merece sanción y condena. Para Beauvoir, eso sucedió (y sucede aún) con la libertad de las mujeres. Las relaciones asimétricas entre los sexos sólo subrayan la "falta" que comete un sexo respecto del otro y, la "mala fe" sobre la que ambos construyeron sus relaciones, sus explicaciones, sus teorías y sus naturalizaciones, aceptándolas como si de verdades supremas se tratara, aunque sólo ante la auto-complacencia del lugar de víctima, las mujeres cometen falta cayendo en la inautenticidad. Las otras han sido (y les son) opresiones infligidas.

A modo de conclusión

Consideramos que, en las páginas precedentes, hemos expuesto el modo en que Beauvoir encaró sus ensayos. Con una notable sensibilidad intelectual fue construyendo, depurando y reforzando a lo largo de los años cuestiones examinadas desde diferentes puntos de mira. Las entrelazó de modo excepcional en el ensayo filosófico, las novelas y hasta en sus memorias autobiográficas. Incluso, ella misma se inscribe en la incompletitud de la vida, y se fue haciendo al escribir, al amar, al arrojar al futuro su proyecto como ancla del presente y del futuro.

Sus ensayos son además de suma importancia no sólo en lo que respecta a la elaboración de una "moral existencialista", siempre postergada por el propio Sartre, sino también para la 
concepción existencialista de la existencia humana en general. En ambos ensayos, su inscripción de la existencia humana en el campo de la moral, no se reduce por cierto al mero esbozo de una cierta perspectiva, sino que pone de manifiesto que es en la dimensión moral donde la existencia humana se asume verdaderamente.

\section{Referencias bibliográficas}

ABELLón, P. Las nociones de "existencia humana" y de "sujeto" en las filosofías de Simone de Beauvoir y Judith Butler a partir de sus recepciones de la Phänomenologie des Geistes (1807) de Hegel. Tesis de doctorado, Facultad de Filosofía y Letras, UBA, 2017.

ÁLVAREZ GONZÁLEZ, Eduardo. La ambigüedad de la existencia en Merlau Ponty. Estudios Filosóficos, 43, 2011, pp.149-177.

Amorós, Celia. Simone de Beauvoir: un hito clave de una tradición. Arenal, 6.1, 1999, pp.113-134.

Amorós, Celia. Ética sartreana de la ayuda y ética feminista del cuidado. Investigaciones fenomenológicas 4, 2008, pp.57-83.

Beauvolr, Simone de. Pyrrhus et Cinéas. Paris, Gallimard, 1944.

BEAUVOIR, Simone de. Pour une morale de l'ambiguité. Paris, Gallimard, 1947.

BEAUvoIR, Simone de. Le deuxième sexe. Paris, Gallimard, v. I y II, 1949.

BEAUVOIR, Simone de. Para una moral de la ambigüedad. Buenos Aires, Schapire, 1956. Traducción: Francisco Jorge Solero.

BEAUVOIR, Simone de. La force de l'âge. Paris, Gallimard, 1960.

BEAUvoIR, Simone de. El segundo sexo. Buenos Aires, Siglo XX, 1962. Traducción: Pablo Palant.

BEAUVOIR, Simone de. Une mort très douce. Paris, Gallimard, 1964.

BEAUVOIR, Simone de. La plenitud de la vida. Buenos Aires, Sudamericana, 1964. Traducción: Silvina Bullrich. 
BEAUVOIR, Simone de. ¿Para qué la acción? Buenos Aires, Siglo Veinte, 1965. Traducción: Juan José Sebreli.

BEAUVOIR, Simone de. Una muerte muy dulce. Buenos Aires, Sudamericana, 1965. Traducción: María Elena Santillán.

BEAUVOIR, Simone de. Tout compte fait. Paris, Gallimard, 1972.

BEAUVOIR, Simone de. Final de cuentas. Buenos Aires, Sudamericana, 1972. Traducción: Ida Vitale.

BEAUVOIR, Simone de.¿̇Hay que quemar a Sade? [1955] Madrid, Mínimo Tránsito, 2000. Traducción: Francisco Sampedro.

BOURDIEU, Pierre, Campo intelectual y proyecto creador. En: POUILLON, J. \& otros, Problemas del estructuralismo, México, Siglo XXI, 1967.

BuTLER, Judith. Sexo y género en El segundo sexo de Simone de Beauvoir. Mora, n ${ }^{\circ}$, Facultad de Filosofía y Letras, UBA. Trad. María Luisa Femenías, 1998. Título original: «Sex and Gender in Simone de Beauvoir's Second Sex» (1986).

Cagnolati, Beatriz; Forte-MÁrmol, Amalia; Gentile, Ana María; VIEGUER, Fabiana. De la Argentina al mundo hispanoamericano: las traducciones con acento porteño de Simone de Beauvoir. En: CAgnolati, B.; Femenías, M. L. (ed.). Las encrucijadas de "el otro sexo", La Plata, Edulp, 2010, pp.13-15.

Cagnolati, Beatriz; FemeníAs, María Luisa; Smaldone, Mariana. Le deuxième sexe: des marques d'époque dans la traduction de "travestie". En: CORBI-SAEZ, M. I.; LLORCA-TONDA, M. A. (ed.). Simone de Beauvoir. Lectures actuelles et regards sur l'avenir // Simone de Beauvoir. Today's readings and glances on the future. Bern, Peter Lang, 2015.

CAgnolati, Beatriz; Femenías, María Luisa (ed.). Las encrucijadas de "el otro sexo". La Plata, Edulp, 2010.

Cagnolati, Beatriz; Femenías, María Luisa; Vukovic, Jovanka. Simone de Beauvoir en Argentina: el rol de las editoriales y de las traducciones en la recepción de su obra. Belas Infiéis, Journal from the Postgraduate program in Translation Studies, Universidade de Brasília, n. 8 (2), 2019, pp.31-49. 
CASALE, Rolando. Algunas coincidencias entre Sartre y Beauvoir sobre el método progresivo-regresivo. En: CAGNOLATI-FEMENíAS, Las encrucijadas de "el otro sexo", 2010, pp.47-54.

CoramidAS, Joan. Breve Diccionario Etimológico. Madrid, Gredos, 1998.

FANON, Franz. Les damnés de la terre. Paris, Maspero, 1961.

FANON, Franz. Los condenados de la tierra. Buenos Aires, F.C.E., 1963. Traducción: Julieta Campos.

FEMENÍAS, María Luisa. Simone de Beauvoir: hacer triunfar el reino de la libertad. Oficios Terrestres, Revista de la Facultad de Periodismo y Ciencias de la Comunicación (UNLP), XIV, 23, 2008, pp.32-45.

FEMENÍAS, María Luisa. La construcción política de las identidades: Un alerta de género. En: Huguet, M.; GonZÁlez MARÍN, C. (ed.). Historia y pensamiento en torno al género. Madrid, Universidad Carlos III, Grupo Koré, 2010, pp.159-190.

FemeníAs, María Luisa; HerRerA, María Marta. El desafío de seguir pensando a Beauvoir. Concordia, 54, 2008, pp.57-77.

FERRERO, A. Narrar el feminismo: teoría feminista y transposición literaria en Simone de Beauvoir. En: FemENíAs, María Luisa (ed.). Feminismos de París a La Plata. Buenos Aires, Catálogos, 2006, pp.17-38.

FIRESTONE, S. La dialéctica del sexo. Barcelona, Kairós, 1973.

FrAISSE, Geneviève. Le privilège de Simone de Beauvoir. Paris, Actes Sud, 2008.

HeIDEGGER, Martin. Identidad y Diferencia. Anthropos, Barcelona, 1990.

KRUKS, Sonia. Gender and Subjectivity: Simone de Beauvoir and Contemporary Feminism. Signs, 18.1, 1992.

LóPEZ-PARDINA, Teresa. Simone de Beauvoir: Una filósofa del siglo XX. Cádiz, Universidad de Cádiz, 1998.

LÓPEZ PARDINA, Teresa. Beauvoir, la filosofía existencialista y el feminismo. Investigaciones Feministas, 2009, pp.99-106

LÓPEZ-PARDINA, Teresa. El bagaje filosófico de Beauvoir. En: SANTA, Ángeles; SEgARRA, Marta (ed.). Simone de Beauvoir, filosofía, literatura y vida. Berna, Peter Lang, 2012. 
LÓPEZ-PARDINA, Teresa. La apelación a Montaigne en la obra filosófica de Simone de Beauvoir. Conferencia. XXI Coloquio internacional "Simone de Beauvoir Society: Presencias plurales de Simone de Beauvoir, cinco años después de las celebraciones del centenario de su nacimiento. Balance, retos y prospecciones de la crítica. Facultad de Filosofía y Letras, Universidad de Alicante, 19 a 22 de Junio de 2013.

Merleau-Ponty, Maurice. Phénoménologie de la perception. Paris, Gallimard, 1945.

MERLEAU-PONTY, Maurice. Fenomenología de la percepción. Barcelona, Agostini-Planeta, 1985.

Merleau-Ponty, Maurice. Merleau-Ponty Existencialista: Selección de Textos. Buenos Aires, Godot-Crítica, 2012.

SANTOS, Magda Guadalupe dos. A ambiguidade ética da aventura humana em Simone de Beauvoir. Cuadernos de Filosofía, 52, F.F. y L (UBA), 2009, pp.57-88.

SARTRE, Jean-Paul. Crítica de la razón dialéctica. Buenos Aires, Losada, 1963. 2 vols. Traducción: Manuel Lamana. [1960]

SARTRE, Jean-Paul. L'être et le néant. Paris, Gallimard, 1971. [1943]

SARTRE, Jean-Paul. El existencialismo es un humanismo. Buenos Aires, Sur, 1978.

SARTRE, Jean-Paul. Cahiers pour une morale, Paris, Gallimard, 1983. Arlette Elkaïm-Sartre (ed.).

SARTRE, Jean-Paul. El ser y la nada. Ensayo de ontología y fenomenología. Buenos Aires, Losada, 2008. Traducción: Juan Valmar.

YounG, Iris M. Is Male Gender Domination the Cause of Male Domination? En: TRABILCOT, Joyce (comp.). Mothering: Essays in Feminist Theory. New Jersey, Rowman \& Allenheld, 1983, pp.129147. 